Hospital Practice

\title{
Is the current use of thyroid scintigraphy rational?
}

\author{
H. Tindall, A.P. Griffiths and N.D. Penn \\ Departments of Medicine and Nuclear Medicine, The General Infirmary, Leeds LS1 3EX, UK.
}

\begin{abstract}
Summary: One hundred and thirty-one consecutive requests for thyroid scintigraphy were analysed to assess their diagnostic contribution to the subsequent medical management of the patient. Forty one per cent of requests were to investigate the presence of a clinically detectable solitary nodule and, of these, one fifth had hot nodules. Diffuse goitres accounted for $38 \%$ of all referrals, but in only two patients (non-toxic hot nodule) did the results change management. A further $11 \%$ of referrals were for multinodular goitres and $8 \%$ for retrosternal goitres. In all cases of goitre no additional useful information was obtained from scintigraphy. It is concluded that thyroid scintigraphy was an unnecessary investigation in approximately $45 \%$ of cases. Its primary role was in the investigation of the solitary nodule and in detecting toxic nodules in thyrotoxic patients who had no evidence of Graves' disease. Greater discrimination of requests would avoid investigating patients unnecessarily and reduce costs.
\end{abstract}

\section{Introduction}

Radio-iodine-123 scintigraphy is a well established and widely available technique for investigating regional thyroid function. ${ }^{1}$ However, it is a moderately expensive investigation which should be requested only when the result is likely to be of practical benefit. To assess how closely the current pattern of referral adhered to this principle we decided to review all thyroid scintigrams performed by a teaching hospital department over one year, together with clinical details obtained from patients' notes, to identify the reason for referral and contribution made by each scintigram to subsequent clinical management.

\section{Materials and methods}

The Nuclear Medicine Department of The General Infirmary at Leeds serves as a referral centre for thyroid scintigraphy for patients in Leeds Western District. Patients were referred to the thyroid clinic either directly by their general practitioner or from hospital clinics within the District. Thyroid scintigraphy was performed two hours after patients had received an intravenous injection of $20 \mathrm{mBq}(0.5 \mathrm{mCi})$ of iodine-123 using a 75 ZLC Siemen's gamma camera.

Correspondence: H. Tindall, M.D., M.R.C.P. Accepted: 23 April 1987
Results

One hundred and thirty-one consecutive requests were received over one year and grouped according to the reason for scintigraphy, as stated on the request card (Table I). The median age of patients was 49.0 years ranging from six months to 91 years and $88 \%$ of the patients scanned were women. There were more $(60 \%)$ requests from physicians than surgeons.

Despite the largest number of requests $(41 \%)$ being confirmation of the presence of a solitary nodule, this diagnosis was confirmed in only 34 of the 54 referrals. Positive scans comprised 11 hot nodules (4 toxic, 7 non-toxic) and 23 cold nodules. Twenty patients were shown to have other conditions, the most frequent being an asymmetrical but otherwise normal gland (Table I).

The second largest category was for further clarification of a clinically palpable diffusely enlarged thyroid gland and this accounted for $38 \%$ of referrals (Table I). Following scintigraphy two patients were found to have non-toxic hot nodules and were therefore kept under review; the remainder of the euthyroid patients were discharged from clinic. Although seven of the patients in this category were thyrotoxic, in no patient could a nodule be palpated, all had diffuse goitres on scintigraphy and scintigraphy did not affect subsequent management.

The diagnosis was confirmed in all 14 patients referred with suspected multinodular goitre on clinical 
Table I Request categories and results obtained for 131 consecutive thyroid scintigrams

Reason for request Number (\% of total

requests) Scintigram result

1. Thyroid nodule

a) ? cold

$50(38 \%)$

b) ? hot

2. Diffuse goitre

a) euthyroid, ? cause

$43(33 \%)$

b) thyrotoxic,? hot nodule

3. Suspected multinodular goitre

4. Suspected retrosternal goitre

$14(11 \%)$

$10(8 \%)$

5. Mass in neck

? malignant

6. Lingual thyroid
$4(3 \%)$

$7(5 \%)$

$2(2 \%)$

23 cold nodules

12 asymmetrical normal gland

7 non-toxic 'hot' nodule

3 thyroglossal cyst

2 regeneration nodule

2 normal diffuse uptake

1 thyroiditis

4 'hot' nodule

25 diffuse uptake

11 asymmetrical normal gland

4 multinodular goitre

2 non-toxic 'hot' nodule

1 scintigram invalid (patient on thyroxine)

7 diffusely increased uptake

14 multinodular goitre

8 retrosternal goitre

2 no retrosternal extension

2 irregular uptake

$1(1 \%)$

1 lingual thyroid examination. Ten requests queried the presence of a retrosternal goitre suspected from chest $\mathrm{X}$-ray and this was confirmed in eight patients. Only two patients complained of mild symptoms (dyspnoea on exertion). None of these patients had further investigations performed.

Two patients had large thyroid carcinomas. They had presented with rapidly enlarging, hard, irregular thyroid glands and both scintigrams showed gross disruption of thyroid activity. Surgery had been planned irrespective of the result of scintigraphy.

One patient was suspected of having a lingual thyroid and ectopic thyroid tissue was successfully demonstrated.

\section{Discussion}

The current cost of the radioactive iodine-123 isotope used in each thyroid scintigram is $£ 20$ per patient. The actual cost to the National Health Service of including physician and technician time and depreciation of equipment probably approaches the fee of $£ 80$ levied by private sector hospitals. In view of the reported high incidence (up to 15\%) of thyroid disease in the community, ${ }^{2}$ it is clear that thyroid scintigraphy must be used selectively. The principal and generally accepted indications for thyroid scintigraphy are given in Table II.

The finding of a solitary nodule in the thyroid demands further investigation. ${ }^{3}$ In most series, this was the largest indication for scintigraphy. $\frac{48}{0} \ddot{0}$ However, it is suggested that the main role of scintigras. phy is in the thyrotoxic patient, to determine whethes overactivity is due to an autonomous hot nodule (Plummer's disease) or diffuse hyperactivity (Graves' disease), to avoid treating patients with Plummer's disease unnecessarily with antithyroid drugs. ${ }^{3,7}$ Aspiration cytology, without prior scanning, has been claimed to be the most cost-effective method of managing suspected solitary nodules, ${ }^{8,9}$ but this is not a practical option until cytologists with sufficient expertise are more generally available. Even so, an important argument in favour of scintigraphy for these patients, even before performing fine needle aspiration if it is available, is to prevent unnecessary investigation of a hot nodule in a euthyroid patient or an asym- \& metrical normal gland. A recent review of surgical practice, in a district general hospital, indicated that thyroid imaging was still used indiscriminately and made no contribution to the final outcome, because despite the result obtained most 'clinically palpable thyroid nodules' were excised (normal glands were

Table II Indications for thyroid scintigraphy

1. presence of a solitary nodule,

2. confirmation of a suspected autonomous hot nodule,

3. follow-up of thyroid carcinoma,

4. demonstration of ectopic thyroid tissue,

5. suspected retrosternal goitre (limited benefit). 
excised in $11 \%$ of patients). ${ }^{10}$ The normal thyroid gland is usually slightly asymmetrical, the right lobe being a little larger than the left and in some patients this asymmetry may simulate nodular enlargement. ${ }^{11}$ A normal result on scintigraphy allays the fears of the patient and clinician, prevents unnecessary surgery and thus is of clinical benefit.

The routine use of thyroid imaging in patients with euthyroid goitres, hypothyroidism or suspected nonpalpable nodules has been shown to provide little information beyond that which could be obtained from careful clinical palpation, yet in two recent series, these categories still accounted for nearly half the requests for scintigraphy. ${ }^{4,5}$ Scintigraphy however, is an essential investigation in the follow-up of patients with differentiated thyroid carcinoma (particularly follicular) to assess the presence or absence of functioning metastases, ${ }^{1,4}$ and for patients with suspected ectopic thyroid tissue.

In conclusion, thyroid scintigraphy should be an essential investigation for patients with thyrotoxicosis, when other features of Graves' disease are absent, to

\section{References}

1. Gross, M.D., Shapiro, B., Thrall, J.H., Freitas, J.E. \& Beierwaltes, W.H. The scintigraphic imaging of endocrine organs. Endocrine Reviews 1984, 5 (2): 221 281.

2. Tunbridge, W.M.G., Evered, D.C., Hall, R. et al. The spectrum of thyroid disease in a community: the Whickham survey. Clin Endocrinol 1977, 6: 207-211.

3. Leading article. The solitary thyroid nodule. Lancet 1985, ii: 870-871.

4. Hamburger, J.I., Miller, M.J., Garcia, M., Meier, D.A. Stoffer, S.S. \& Taylor, C.I. Is thyroid imaging an overutilized diagnostic procedure? In Controversies in Clinical Thyroidology. Part I. Springer, Berlin, 1981, pp 1-20.

5. Reasner, C.A. \& Isley, W.L. Thyroid scanning in patients with suspected thyroid disease. Ann Intern Med 1985, 102: 209-210.

6. Maxon, H.R., Hertzberg, V., Vasavada, P., Pu, M.Y. \& Volarich, D. The continuing impact of thyroid scintigra- avoid missing an autonomous hot nodule. A uniform policy on the management of patients with solitary nodules needs to be encouraged, but for the present, we would continue to recommend scintigraphy for these patients. However, scintigraphy has been shown to be of little practical value in the management of euthyroid patients with diffuse or multinodular goitres, or patients with hypothyroidism and therefore should not be requested.

Our experience shows that thyroid scintigraphy could be used more selectively and economically and that clinicians should not request this investigation when they know in advance that the outcome will not influence management.

\section{Acknowledgements}

We wish to thank the technical staff of the Nuclear Medicine Department for performing the isotope scintigrams and to Dr J.A. Davies for his helpful advice in preparing this manuscript.

phy on the diagnosis of thyroid enlargement. Clin $\mathrm{Nucl}$ Med 1986, 11: 306-307.

7. Cooke, S.G., Ratcliffe, G.E., Fogelman, I. \& Maisey, M.N. Prevalence of inappropriate drug treatment in patients with hyperthyroidism. $B r$ Med $J$ 1985, 291: 1491-1492.

8. Walker, J., Findlay, D., Amar, S.S., Small, P.G., Wastie, M.L. \& Pegg, C.A.S. A prospective study of thyroid ultrasound scan in the clinically solitary thyroid nodule. Br J Radiol 1985, 58: 617-619.

9. Van Herle, A.J. (Moderator, UCLA Conference). The thyroid nodule. Ann Int Med 1982, 96: 221-232.

10. Dawson, P.M. The surgical treatment of thyroid disease in a district general hospital. Br J Clin Pract 1985, 37: 220-224.

11. Wilson, T.D. \& Foster, D.W. (eds). Williams Textbook of Endocrinology. 6th Edition. W.B. Saunders Company, Philadelphia, 1981, pp 682-816. 